\title{
Flipped Classroom Strategies for CS Education
}

\author{
Mary Lou Maher, Celine Latulipe, Heather Lipford, Audrey Rorrer \\ Department of Software and Information Systems and Center for Education Innovation \\ University of North Carolina Charlotte \\ \{m.maher, clatulip, heather.lipford, audrey.rorrer\}@uncc.edu
}

\begin{abstract}
The basic principles of a flipped classroom teaching method are to deliver content outside of the class and to move active learning into the classroom. There are many strategies for delivering the content online, such as having instructors prepare online lectures, wrapping the course around a MOOC, and curating online videos from various sources. There are also many strategies for including active learning in the classroom that go beyond providing programming labs, and can include various forms of peer instruction. In this paper we describe our experiences flipping four different computer science classes across multiple semesters over two years. This breadth of experience with classroom flipping has enabled us to compare strategies and approaches and develop an understanding of which approaches appear to work under which circumstances. We discuss how we structured out-of-class preparatory work, how we created or sourced online videos, how we used active learning activities in-class to scaffold skills development and identify students' misconceptions, and how we structured teams for in class activities. This paper contributes a set of flexible strategies to consider for provision of curricular content out-of-class, structuring students' preparatory work, applying active learning of skills and concepts, and leveraging social interaction and peer instruction for CS education. We present the impact of our approaches based upon leading indicators of course evaluations and student surveys. We discuss lessons learned and students' responses to our strategies.
\end{abstract}

\section{Categories and Subject Descriptors}

K.3.2 [Computer Science Education]

\section{General Terms}

Education

\section{Author Keywords}

Flipped classroom; online video; strategies for active learning

\section{INTRODUCTION}

The number of alternative teaching methods being explored in Computer Science (CS) education is increasing in an attempt to address both pedagogical and financial challenges, such as

Permission to make digital or hard copies of all or part of this work for personal or classroom use is granted without fee provided that copies are not made or distributed for profit or commercial advantage and that copies bear this notice and the full citation on the first page. Copyrights for components of this work owned by others than ACM must be honored. Abstracting with credit is permitted. To copy otherwise, or re-publish, to post on servers or to redistribute to lists, requires prior specific permission and/or a fee. Request permissions from Permissions@acm.org.

SIGCSE'15, March 4-7, 2015, Kansas City, MO, USA.

Copyright is held by the owner/author(s). Publication rights licensed to ACM. ACM 978-1-4503-2966-8/15/03 ...\$15.00.

http://dx.doi.org/10.1145/2676723. 2677252. creating active learning experiences with increasing financial pressures [8]. Our department is developing strategies for flipped classroom teaching with a goal to change to this model of teaching for a majority of the courses taught in our Bachelors and Masters degree programs. This is part of a university-wide effort to increase retention and reduce the time to graduation by providing learning activities that engage students in the material with more hands-on experiences and more connection with other students.

A flipped, or inverted, classroom teaching method has two main components: deliver instructional content outside of the classroom (typically online) and move active learning into the classroom ${ }^{1}$. These two components open up four instructional design challenges: how to structure the student's preparatory work; how to deliver the instructional content out-of-class; how to design active learning activities to use in-class to scaffold learning, identify misconceptions and allow students to practice critical skills; and finally, how to structure student interaction to best leverage social learning and peer instruction. In adopting a flipped classroom approach, strategies for these four instructional design components are varied and flexible.

This paper describes how we have dealt with each of these four instructional design challenges in a variety of different ways, always considering the drain on instructional resources associated with major curricular changes. Flipping classrooms can be resource intensive, especially the first time a class is flipped, though this is similar to the resources required to develop any course from scratch. It is our hope that the experiences we report can help computer science educators better understand the options available to them in converting a CS class to the flipped model.

\section{BACKGROUND}

Since the earliest attempt to use a flipped classroom method to teach an economics course [9], educators have used this teaching method in many courses including Mathematics [10], Biology [12], Business Management [14], Industrial Engineering [16] and Computer Science [5]. The flipped classroom approach has been used in both small and large courses with hundreds of students. In large classrooms however, the students were divided into smaller groups when they were working on class activities [14].

Flipped courses require students to come to the class after completing significant preparatory work, so that they can participate in the class activities. This prep work typically includes learning materials such as lectures and presentations delivered via podcasts or video-on-demand services [14, 16], but may also include narrated or animated PowerPoint presentations, online tutorials, and textbook reading.

\footnotetext{
${ }^{1}$ http://www.knewton.com/flipped-classroom/
} 


\begin{tabular}{|c|c|c|c|c|c|}
\hline Course & $\begin{array}{l}\text { Prep Work Required of } \\
\text { Students }\end{array}$ & Video Sourcing & In-Class Activities & Group/Team work uses & $\begin{array}{c}\text { Estimated \# Hours } \\
\text { Sourcing or Creating } \\
\text { Videos } \\
\end{array}$ \\
\hline $\begin{array}{l}\text { ITIS } 3150 \text { (Rapid Prototyping } \\
\text { and Interface Building) }\end{array}$ & $\begin{array}{l}\text { Read Textbook, Watch } \\
\text { Videos, Take Online Quiz }\end{array}$ & $\begin{array}{l}26 \text { videos created by } \\
\text { instructor, } 8 \text { videos } \\
\text { sourced from web }\end{array}$ & $\begin{array}{l}\text { Creating Prototypes, Testing } \\
\text { Prototypes, Critiquing } \\
\text { Prototypes, Design Pattern } \\
\text { Identification }\end{array}$ & $\begin{array}{l}\text { Ad hoc teams/pairs for in } \\
\text { class activities }\end{array}$ & $\begin{array}{l}300 \text { hours } \\
\text { (videos made over course } \\
\text { of three semesters, adding } \\
\text { more each offering) }\end{array}$ \\
\hline ITIS $6400(\mathrm{HCI})$ & $\begin{array}{l}\text { Watch Videos, Read } \\
\text { Assigned Articles }\end{array}$ & $\begin{array}{l}\text { Stanford } \mathrm{HCl} \text { MOOC, plus } \\
\text { a few videos created }\end{array}$ & $\begin{array}{l}\text { Homework quiz, peer grading } \\
\text { of quiz, design and } \\
\text { evaluation skill practice } \\
\text { activiites such as mock } \\
\text { interivews, mock surveys, } \\
\text { heuristic evaluations, etc. }\end{array}$ & $\begin{array}{l}\text { Course has semester-long } \\
\text { team project, so teams } \\
\text { generally sat together in } \\
\text { class and did activities } \\
\text { together }\end{array}$ & $\begin{array}{l}30 \text { hours } \\
\text { (reviewing MOOC videos } \\
\text { to create homework } \\
\text { quizzes, plus time to make } \\
\text { extra videos to augment } \\
\text { curriculum) }\end{array}$ \\
\hline $\begin{array}{c}\text { ITIS } 2300 \text { (Web Applications } \\
\text { Development) }\end{array}$ & $\begin{array}{l}\text { Watch Videos, Critique } \\
\text { Videos, Read Textbook } \\
\text { (also encouraged to enter } \\
\text { programs demonstrated in } \\
\text { videos) }\end{array}$ & $\begin{array}{l}\text { Sourced from the web } \\
\text { (mostly YouTube and } \\
\text { thenewboston.com) }\end{array}$ & $\begin{array}{l}\text { Homework Quizzes, } \\
\text { Pseudocode problems, } \\
\text { coding demonstrations, other } \\
\text { short group activities }\end{array}$ & $\begin{array}{l}\text { Ad hoc teams created in } \\
\text { class each week }\end{array}$ & $\begin{array}{l}40-50 \text { hours } \\
\text { sourcing/reviewing videos }\end{array}$ \\
\hline $\begin{array}{l}\text { ITIS } 1212 \text { (Introduction to } \\
\text { Media Programming) }\end{array}$ & $\begin{array}{l}\text { Watch videos, Read } \\
\text { Textbook, Enter \& Submit } \\
\text { Textbook Programs, Take } \\
\text { Online Quiz }\end{array}$ & $\begin{array}{l}95 \% \text { sourced from the } \\
\text { web, about } 5 \text { videos } \\
\text { created by instructor }\end{array}$ & \begin{tabular}{|l|} 
Peer instruction clicker \\
quizzes, pseudocode \\
problems, Parsons' problems, \\
peer critiquing of solutions
\end{tabular} & $\begin{array}{l}\text { Assigned lightweight } \\
\text { teams of five students sit } \\
\text { together and do all } \\
\text { activities together }\end{array}$ & $\begin{array}{l}70 \text { hours } \\
\text { sourcing/revieiwng and } \\
\text { creating videos }\end{array}$ \\
\hline
\end{tabular}

Table 1: Flipped classes, their structure elements, and hours spent on video prep by instructors.

Active learning is a central component of the flipped class teaching method [1]. Students spend time in-class working on activities such as solving problems, writing code, design tasks, or discussing concepts with others. This creates a learning environment where students learn by collaborating with their peers. Many studies have shown that working with peers in-class activities improves overall learning, increases student confidence and makes coding fun $[5,7]$. Classroom quizzes have also been used as an effective mode of instructor-student interaction and many new technologies including 'Clickers' have successfully been used to foster learning through quizzing [11].

Developing material for flipped classrooms is a challenging task and different instructors have used different approaches. Some institutions and instructors are already recording their lectures for the purpose of online courses, which makes it easy for these instructors to leverage those resources in their flipped classes [4, $5,16]$. However, this tends to mean very long videos are created. Recorded lectures are not liked by all students as many reported that sometimes the lectures were too long and not suited for difficult course materials [4]. Most students suggested that optimal length of video lectures should be 15-30 minutes [5, 16].

The amount of time required to prepare for a flipped class depends on the amount of content to be provided to the students. Some instructors have reported 35 hours of work to create an hour of lecture material [8], while others have reported less [3]. Instructors are also required to develop in-class learning activities and quizzes. The amount of time required for grading also increases as weekly learning activities need to be evaluated regularly [4].

In this paper we add to this literature with a focus on the strategies appropriate for learning both skills and concepts associated with computing courses. Specifically, we have developed and applied our strategies to an introductory programming course, a web application development course, a rapid prototyping and interface building course and a human-computer interaction (HCI) course. In the following section we describe these courses and how they developed into flipped classes. We then compare our various approaches to assigning preparatory work to students, to delivering instructional content online, to development of strategies for in-class activities, and to structuring group work. We discuss preliminary results showing a trend towards a positive attitude from students on the benefits of flipped classrooms.

\section{FLIPPED COMPUTING COURSES}

We developed our strategies for flipped classrooms for 4 different courses, which have each been taught multiple times. These courses, the terms they were taught and their enrollments are shown in Table 2, ordered by when these classes began to be flipped. We began to formally study our flipped class approaches in 2013, so there is no survey data for earlier semesters.

\begin{tabular}{|c|c|c|c|c|}
\hline Course & Semester & Enrollment & Responses & $\begin{array}{c}\text { Response } \\
\text { Rate }\end{array}$ \\
\hline ITIS 3150 (Rapid Prototyping & Fall 2012 & 33 & & \\
and Interface Building) & Spring 2013 & 30 & & \\
& Fall 2013 & 40 & 29 & $73 \%$ \\
ITIS 6400/8400 (Graduate HCI) & Spring 2013 & 11 & & \\
& Spring 2014 & 50 & 41 & $82 \%$ \\
ITIS 2300 (Web Applications & Spring 2013 & 93 & & \\
Development) & Fall 2013 & 75 & 61 & $81 \%$ \\
ITIS 1212 (Introduction to & Spring 2014 & 66 & 36 & $55 \%$ \\
Media Computation) & Fall 2013 & 87 & & \\
& Spring 2014 & 62 & 46 & $74 \%$ \\
\hline
\end{tabular}

Table 2: Flipped classes, enrollments and survey response rates across different semesters.

Rapid Prototyping and Interface Building: This is an upper year course with typically $30-40$ students in a class. The topics covered include methods for quickly prototyping a user interface using sketches, paper mock-ups, wireframes, and interactive digital prototypes, as well as how to create coded prototypes using a GUI builder. Students learn a vocabulary of design patterns and learn how to create and critique many alternative designs. This class was originally developed as a traditional lecture class that was augmented by occasional hands-on activities. Over a few years, the instructor slowly migrated the class to a flipped class structure, creating more videos each time the course was offered.

Human Computer Interaction: This is a graduate level course with 10-50 students in the class. The topics covered include needfinding methods, prototyping, design, and evaluation. This class 
was originally developed as a traditional lecture class, augmented with occasional activities. The instructors were beginning to develop videos to flip this class when Coursera began offering the HCI MOOC course. The isntructors then requested and received permission from Coursera and the Corsera instructor to 'wrap' the HCI course around the MOOC videos.

Web Applications Development: This is a 2000 level course with typically $60-90$ students in a class. The topics learned include various web services languages (html, css, javascript, and jquery), as well as design and layout considerations. This class was originally taught in a traditional lecture format, but was fully flipped beginning in 2013. The videos in this class have been curated from various online sources.

Introduction to Media Computation: This is a newly introduced introductory programming course in which students learn Java through a media computation approach [5]. This class has a typical enrollment of 60-100 students. This class was developed over the summer of 2013, and was designed as a flipped class from the start. Thus, no effort was expended creating lectures or slides, rather, significant effort was put into curating introductory programming videos from the web and developing labs, active learning activities and peer instruction quizzes.

\section{STRUCTURING THE WORKFLOW}

There are many alternatives for structuring the timing for the delivery of learning materials and activities in a flipped classroom. Here we present alternatives for temporal flow of learning and the expectations for students' preparatory work, finishing with some lessons learned.

\subsection{Temporal Flow}

The temporal structure each week is: students engage with the online instructional content as their preparatory work first and then participate in small group activities during the scheduled class times. In the programming courses a weekly group activity is a programming lab session where they try out the new skills in a structured lab activity with pair programming. In all flipped courses, students engage in group activities such as role playing, design and critique, and problem solving. For the programming courses, the programming lab is scheduled before the problem solving activity so that they can reflect on the skills learned in lab.

\subsection{Preparatory Work}

While standard classes may have assigned reading for homework, it is often the case that students have no real incentive to complete the reading, since the material will be covered in lecture. Because there is no lecture in flipped classes, the preparatory work is the only way for students to get the needed instructional content. Table 1 shows the variety of preparatory work assigned across the four different classes. In all cases there are readings and videos. In the Media Computation and Rapid Prototyping class students were required to complete a Moodle quiz designed to check that they had completed the prep work before attending class. In the web application and HCI class, quizzes on the homework were an activity completed in class. Students in the programming courses were required or encouraged to enter the programs from the videos and/or textbook as part of their prep work.

\subsection{Lessons Learned}

Having students practice skills before diving deeply into discussions of conceptual material allows the discussion of concepts to be contextualized in the activities already completed.
This makes class activities and discussion less abstract and much more meaningful. We also found that providing explicit structure is helpful, particularly for freshmen, as there are more course components to track. The Moodle (the UNCC LMS) autocompletion feature was useful to specify the order in which preparatory activities had to be completed, and allowed us to deny access to items like quizzes until other preparatory activities were marked complete.

In early semesters students expressed initial concerns about having graded labs, quizzes, and activities prior to some sort of in-class discussion or instruction by a faculty member. We found that as we improved upon the structure, communicating the purpose and benefits of that structure alleviated many of these concerns.

\section{PROVISIONING VIDEO INSTRUCTION}

Here we outline three strategies for providing video instruction and our lessons learned.

\subsection{Creating videos}

The first strategy is to create our own videos, although this is the most time consuming. There were very few online resources available for the Rapid Prototyping course, so the only option was to develop and record customized video lectures. As has been previously noted, video preparation was time consuming because online lectures are shorter than a traditional classroom lecture. Because of the time involved, the instructor took two semesters to convert all lectures into succinct, effective videos. Videos were also created to fill gaps in the out sourced videos for the Media Computation and HCI courses.

\subsection{Curating videos}

Collecting and curating online videos has many advantages. In the Media Computation and Web Applications courses we curated multiple online videos for each topic covered. We found videos through YouTube and other instructional sites, and included videos from a variety of authors. We also recommended optional videos for additional resources or for more advanced students. Many videos showed a computer screen, with the author typing and narrating a code example. Videos ranged in length from 5 to 35 minutes.

Curating videos became a part of the learning experience for the students. In the Web Applications class students were required to provide critiques of the videos they watched. The students' critiques gave us insight into what aspects of the video instruction they understood, liked and disliked. Through the critique, the students articulated their understanding of the role of the video instruction and how it contributes to their learning. Since this critique was submitted by the students on a weekly basis rather than at the end of the semester, it became part of their learning experience.

\subsection{Wrapping a MOOC}

In the $\mathrm{HCI}$ course, we used the videos from the Coursera $\mathrm{HCl}$ course $^{2}$, with permission from Coursera and from Scott Klemmer, the instructor of the MOOC. We made the videos available from a link on the UNCC course page or students could visit the Coursera page. The Coursera content matched our needs for lecture-based content, and we added supplemental content for additional topics.

\footnotetext{
${ }^{2}$ https://www.coursera.org/course/hciucsd
} 


\subsection{Lessons Learned}

Each instructor gathered or developed videos as best fit their course. The right-most column of Table 1 gives an estimate of instructional time dedicated to creating and/or curating videos across the different courses. Even when videos are curated rather than created, the process of curating videos for a whole course takes a significant amount of time.

We wanted the students to benefit from learning course concepts from more than one perspective. This was particularly important in the Web Applications course, where students had a wide range of expertise from those who had never seen HTML to some who had taken courses in high school or even had some job experience. Providing a range of videos let students find resources that matched their current experience levels and expanded upon what we could cover during the semester.

Students utilized the video resources differently than a lecture, particularly for programming topics. They commented that they were able to follow along with the code on their own, and pause, rewind, and replay as needed. Presenting such examples inside a classroom, with students following along on their own computers, is much more difficult. One student said: "The good thing about videos is you can pause/play as you please and rewind/fastforward when necessary, ..."

The use of videos from various authors demonstrated the variety of resources that exist on the Internet to help teach and provide examples of code and programming concepts. The diversity in resources promotes self-exploration to students, which they demonstrated later in their homework. Many referred back to the video tutorials while completing their homework, something that is not possible if the lecture is only available live in class. One student posted: "As I am finishing up my final website, I am going back over the video tutorials for last minute help and ideas. They are much easier to understand at the end of the semester!"

However, a disadvantage of curated videos was that they did not always present a topic at a conceptual level, nor were they tailored to the common misunderstandings or challenges that students in a particular class have. Students often described situations in which the author of the video didn't present information clearly. "I thought these videos were very unhelpful. The guy just seems to be putting code on the screen and keeps saying "we will get to that later" and just continues to build his website."

To alleviate some of these issues, we provided a brief high level conceptual explanation in class the week prior to the topic. However, some students reported this was not sufficient and they would have appreciated more conceptual information within the videos themselves. We are considering the addition of our own short conceptual lecture videos to address this issue.

Another drawback of online instruction is that watching videos is a solitary activity. We are trialing opportunities for students to comment, critique, and reflect on online videos in a more social way, through the Video Collaboratory [14]. The Video Collaboratory is an online system that allows groups of students to privately and asynchronously discuss videos through text and sketch annotations. For example, in our current HCI course, students are required to watch the videos inside the Collaboratory, and annotate them weekly. Members of the group can view each other's annotations and add to the discussion. We plan to extend the use of the Collaboratory to more courses as we gain experience in its use. We believe that the 'shared watching experience' in small groups of 5-10 students creates a more intimate and less intimidating forum for discussion around educational videos.

\section{IN-CLASS ACTIVITIES}

In addition to creating or collecting online videos, one of the other major challenges for flipped classroom instruction is creating class activities that teach course concepts and skills through active learning. For our programming courses, labs are a critical active learning component. But, the real challenge is to find active learning activities to replace the time that would traditionally be used for lecturing. We have developed two main types of in-class activities: group problem solving and flexible quiz activities.

\subsection{Pair Programming Labs}

Similar to many programming courses, the Web Applications and Media Computation courses include weekly pair programming lab sessions. Typically, students were asked to edit and extend existing code. In later parts of the course students had to code from scratch. The tasks covered specific skills and language constructs each week. Lab activities were carefully structured to enable completion within the time allocated, assuming the student had prepared. We have tested many strategies for pairing students in the lab, including gender pairing and randomly changing the pair each week or every other week. The purpose of switching partners frequently is to help the students get to know a larger number of students in their class and to make sure that students don't play the same role with the same person each week.

The use of pair programming was successful, and seemed to encourage students to work both with their partner, and over time with other students, to answer questions and learn new techniques. Alternating the pairs was also important, as the skill and knowledge level of students was quite varied.

\subsection{Group Problem Solving Activities}

For the non-programming courses, and on the non-lab day for the programming-based courses, the problem solving activity is a highly structured activity that is timed. Typically, students work in small groups to encourage conversation and peer instruction. In the HCI and Rapid Prototyping classes, these activities generally involved students practicing design and evaluation skills. For example, in the HCI class, when teaching needfinding, one or two students in a group were asked to develop a persona and role play a typical user, while the others in the group prepared interview questions and conducted an interview. In Rapid Prototyping, student groups utilized different techniques to create prototypes at different levels of fidelity. In Web Applications, activities included finding existing web pages to demonstrate weekly topics, drawing conceptual diagrams and writing pseudo-code. In Media Computation students often solved problems by writing pseudocode or doing other paper problem solving activities.

In all courses, we emphasize collaboration and critiquing. These activities are then built upon later when students complete their assignments, which test their application of the learned skills without teacher supervision. In the HCI and Rapid Prototyping courses, students can re-use and extend some of their in-class activities as part of their assignments.

\subsection{Flexible Quiz Activities}

In flipped classrooms, instructors often use quizzes to incentivize students to watch videos and come to class prepared. We also use quizzes as learning activities, especially in the programming courses. This idea is based on the finding that retrieving 
information from memory improves long term retention [13]. The quiz generally comprised multiple choice questions about textbook and video content, or about code fragments. In contrast to the problem solving activity, the quiz tests and reinforces conceptual knowledge where the problem solving activity provides scaffolding for programming skills or HCI methods.

Throughout the four courses, different techniques were used to make the quiz an activity that encouraged peer learning and the discovery and clarification of misconceptions. We developed several strategies for student interaction around quizzes:

1. Students complete the quiz labeled only with their id number. Quizzes are redistributed to others for peer grading. The instructor directs the peer grading by discussing why particular answers are right or wrong for each question.

2. Students complete the quiz on their own, and then are asked to compare and discuss their answers with the students sitting near them until all students sitting near each other have the same answers. Each student's quiz is graded separately.

3. Students form groups and each group completes a quiz, again, ensuring that the answers are the consensus of the group. All students in a group get the same grade.

4. Students complete the quiz using clickers and can talk to each other before answering. The answers are aggregated on the screen in front of the room, and instructors re-poll as needed. Various game-like methods are used to create competition.

5. Student groups create a quiz based on their annotated videos. Each group takes another group's quiz and the group that created the quiz grades the answers. In this way each group creates a quiz, takes a quiz, and grades a quiz.

In all variations on the way the quiz was administered, the quiz provided the focus for the peer learning and the discovery of misconceptions. When misconceptions were uncovered, the instructors conducted impromptu mini-lectures. Thus, the quiz activities could often take up a significant portion of a class.

\subsection{Lessons Learned}

All of the in-class activities are designed to be collaborative in some way. We promote peer instruction for the following reasons: the social aspect of peer instruction helps students get to know other students and making friends is important for program retention; when students are socially relaxed they are likely to learn more; some students have an easier time learning from peers than from professors; learning from peers demonstrates that there are many sources of knowledge; learning from peers exposes students to different perspectives on issues; and, teaching peers helps students clarify and solidify their own understanding of course concepts.

In programming labs, we use pair programming with frequent partner switches throughout the semester. In our workshop classes we facilitate student collaborations in a variety of ways. In HCI there is a high-stakes group project and teams typically sit together and work together on in-class activities. In the Web Applications and Rapid Prototyping courses, ad hoc groups or pairs are formed for in-class activities. This works well in upper year classes where students are typically comfortable forming teams and students have friends that they want to work with.

In the Media Computation course, we created lightweight teams consisting of 5 students per team. These teams sit together in assigned seating during the peer instruction workshops each week.
These teams are called 'lightweight' because there is no direct link between team activities and an individual's final grade, though the team works together all semester. We find this works well for freshmen courses where students don't know many people.

We found that emphasizing skill development during class activities enabled us to create more open-ended homework assignments that encouraged creativity. For example, in the Web Applications course, students created a website to promote a business or hobby. Many of the websites created were more professional, with greater content, than assignments from prior (non-flipped) years.

\section{STUDENT FEEDBACK}

The standard student evaluation forms administered at the end of the semester typically start with statements about the instructor. For example "My instructor displays a clear understanding of the course topics." "My instructor has an effective style of presentation." These create an impression that the quality of the course depends on how much the instructor knows rather than on how much the student learned. While it may be appropriate to evaluate the quality of the instructor, flipped classrooms require a survey that primes students to think about the quality of their learning experience. We administered a survey to gather student perceptions about the flipped classroom approach to provide formative evaluation and immediate feedback from students.

\begin{tabular}{|l|c|c|}
\hline Survey Item & Mean & SD \\
\hline $\begin{array}{l}\text { I felt I was more able to learn at my own pace } \\
\text { (compared to previous courses). }\end{array}$ & 5.06 & 1.41 \\
\hline $\begin{array}{l}\text { I was more able to recognize when I didn't understand } \\
\text { something (compared to previous courses). }\end{array}$ & 5.00 & 1.34 \\
\hline $\begin{array}{l}\text { I looked at extra information beyond the provided } \\
\text { material (compared to previous courses). }\end{array}$ & 4.54 & 1.60 \\
\hline $\begin{array}{l}\text { I felt that I learned more during class time (compared } \\
\text { to previous courses). }\end{array}$ & 4.89 & 1.59 \\
\hline $\begin{array}{l}\text { I felt that I learned more outside of class time } \\
\text { (compared to previous courses). }\end{array}$ & 4.81 & 1.54 \\
\hline How helpful were the online videos for learning? & 5.17 & 1.48 \\
\hline $\begin{array}{l}\text { Learning from other students is just as good as } \\
\text { learning from the teacher. }\end{array}$ & 4.76 & 1.47 \\
\hline $\begin{array}{l}\text { Other students helped me to understand the right } \\
\text { answers while we were discussing clicker questions. }\end{array}$ & 5.04 & 1.17 \\
\hline $\begin{array}{l}\text { I helped other students to understand the right } \\
\text { answers while we were discussing clicker questions. }\end{array}$ & 4.97 & 1.20 \\
\hline $\begin{array}{l}\text { Explaining things to other students helped me to } \\
\text { understand them better. }\end{array}$ & 5.35 & 1.09 \\
\hline How mentally demanding was the course? & 4.55 & 1.24 \\
\hline $\begin{array}{l}\text { How successful were you in accomplishing what you } \\
\text { were asked to do in this course? }\end{array}$ & 4.35 & 1.72 \\
\hline $\begin{array}{l}\text { How hard did you have to work to accomplish your } \\
\text { level of performance in this course? }\end{array}$ & 4.95 & 1.36 \\
\hline
\end{tabular}

Table 3: Post course student survey average responses.

The post-course survey was conducted across four courses with responses from a total of 213 students. While each survey contained course-specific items, the common part of the survey consisted of 13 Likert-type items with a 7-point rating scale, with 
7 being strong agree/very high. There were also three open-ended items inquiring about likes, dislikes and suggestions. The majority of students were pleased with the flipped course approach. The majority of items received positive ratings above 4, with average ratings above 5 , and with low standard deviations, an indication of consistency in ratings. Item means are presented in Table 3. Highest average ratings were "explaining things to others," and the online videos. Students also reported moderate to high ratings of feeling successful in the courses.

Themes from the open-ended items indicated that the students were more engaged with the material and with their peers as a result of this approach. The majority of comments were positive and suggest that students liked having hands-on engagement. For example, "I liked the fact that it was more hands-on than other classes;" and "I liked how the lab actually helped me learn in the class and all of the videos were helpful." Responding to the disliked item, students indicated that they needed more lab time to complete assignments, and a few suggested that having quizzes before lab was undesirable. The majority of students presented constructive feedback, with only a minority complaining about wanting more in-class lecture. While early informal feedback indicated concern about the lack of lectures, most students' perceptions changed by the end of the semester when we had them complete the survey and they had positive responses to learning concepts from online videos. However, a small percentage of students at the end of the semester presented concerns about this approach to teaching: "We were graded on topics not covered then lectured after;" and "time spent outside of the classroom watching videos made me feel like the class was online." These comments show that even at the end of the semester, a few students had not realized that the content provided in the online instruction and the textbook was part of the learning experience. We are responding to this concern by better communicating our intentions and pedagogical goals.

\section{CONCLUSIONS}

We have presented our experiences in developing flipped courses: the temporal structure, alternative sources for video instruction and strategies for active learning. Video instruction precedes skills development and concept learning, in-class lab activities scaffold for open ended homework projects and promote peer learning, and in-class quizzes lead to discovery of misconceptions. We have shown how these strategies were implemented across a variety of computing courses and how student perceptions are generally positive about the learning experience. The perception of instructors not spending sufficient time on teaching is important to address, particularly since this method can involve more preparation time (see Table 1) than a traditional class.

Future directions for investigating the impact of this method are analyses of student learning outcomes, including comparisons of grade performance before and after the implementation of the flipped classroom approach, and analyses of subsequent course outcomes as we determine how well this approach prepares students in their academic progression.

\section{REFERENCES}

[1] Auster, E. R., \& Wylie, K. K. (2006). Creating active learning in the classroom: A systematic approach. Journal of Management Education, 30(2), 333-353.
[2] Bruff, D., Fisher, D., McEwen, K. and Smith, B. 2013. Wrapping a MOOC: Student perceptions of an experiment in blended learning. Journal of Online Learning and Teaching. 9, 2 (Accepted 2013).

[3] Day, J.A. and Foley, J.D. 2006. Evaluating a Web Lecture Intervention in a Human-Computer Interaction Course. IEEE Transactions on Education. 49, 4 (2006), 420-431.

[4] Gannod, G.C., Burge, J.E. and Helmick, M.T. 2008. Using the inverted classroom to teach software engineering. ACM/IEEE 30th International Conference on Software Engineering, 2008. ICSE '08 (2008), 777-786.

[5] Gehringer, E.F. and Peddycord,III, B.W. 2013. The inverted-lecture model: a case study in computer architecture. Proceeding of the 44th ACM technical symposium on Computer science education (New York, NY, USA, 2013), 489-494.

[6] Mark Guzdial. 2013. Exploring hypotheses about media computation. In Proceedings of the ninth annual international ACM conference on International computing education research (ICER '13). ACM, New York, NY, USA, 19-26.

[7] Hanks, B. 2006. Student attitudes toward pair programming. Proceedings of the 11th annual SIGCSE conference on Innovation and technology in computer science education (New York, NY, USA, 2006), 113-117.

[8] Kaner, C. and Fiedler, R. 2005. Inside Out: A Computer Science Course Gets a Makeover. (2005).

[9] Lage, M.J., Platt, G.J. and Treglia, M. 2000. Inverting the Classroom: A Gateway to Creating an Inclusive Learning Environment. The Journal of Economic Education. 31, 1 (Jan. 2000), 30-43.

[10] Lockwood, K. and Esselstein, R. 2013. The inverted classroom and the CS curriculum. Proceeding of the 44th ACM technical symposium on Computer science education (New York, NY, USA, 2013), 113-118.

[11] Mayer, R., Stull, A., Almeroth, K., Bimber, B., Chun, D., Bulger, M., Campbell, J., Knight, A. and Zhang, H. Using Technology-Based Methods to Foster Learning in Large Lecture Classes: Evidence for the Pedagogic Value of Clickers.

[12] Moravec, M., Williams, A., Aguilar-Roca, N. and O'Dowd D.K. 2010. Learn before lecture: A strategy that improves learning outcomes in a large introductory biology class. CBE life sciences education. 9, 4 (2010), 473-481.

[13] Roediger, H.L. and Karpicke, J.D. 2006. Test-enhanced learning: taking memory tests improves long-term retention. Psychological science. 17, 3 (2006), 249-255.

[14] Schullery, N.M., Reck, R.F. and Schullery, S. 202. Toward solving the high enrollment, low engagement dilemma: A case study in introductory business. International Journal of Business, Humanities and Technology. 1, 2 (2011), 1-9.

[15] Singh, V., Latulipe, C., Carroll, E., and Lottridge, D. The Choreographers Notebook A video annotation system for dancers and choreographers. In ACM Creativity \& Cognition 2011. ACM, 197-206, 2011.

[16] Toto, R. and Nguyen, H. 2009. Flipping the work design in an industrial engineering course. Proceedings of the 39th IEEE international conference on Frontiers in education conference (Piscataway, NJ, USA, 2009), 1066-1069. 